\title{
The PI3K/Akt pathway upregulates Id 1 and integrin $\alpha 4$ to enhance recruitment of human ovarian cancer endothelial progenitor cells
}

\author{
Yajuan Su, Lei Zheng ${ }^{*}$, Qian Wang ${ }^{*}$, Jie Bao, Zhen Cai, Ailan Liu
}

\begin{abstract}
Background: Endothelial progenitor cells (EPCS) contribute to tumor angiogenesis and growth. We aimed to determine whether inhibitors of differentiation 1 (Id1) were expressed in circulating EPCs of patients with ovarian cancer, whether Id1 could mediate EPCS mobilization and recruitment, and, if so, what underlying signaling pathway it used.

Methods: Circulating EPCs cultures were from 25 patients with ovarian cancer and 20 healthy control subjects. Id1 and integrin $\alpha 4$ expression were analyzed by real-time reverse transcription-polymerase chain reaction and western blot. EPCs proliferation, migration, and adhesion were detected by MTT, transwell chamber, and EPCs-matrigel adhesion assays. Double-stranded DNA containing the interference sequences were synthesized according to the structure of a pGCSIL-GFP viral vector and then inserted into a linearized vector. Positive clones were identified as lentiviral vectors that expressed human Id1 short hairpin RNA (shRNA).

Results: Id 1 and integrin $\alpha 4$ expression were increased in EPCs freshly isolated from ovarian cancer patients compared to those obtained from healthy subjects. siRNA-mediated Id 1 downregulation substantially reduced EPCs function and integrin $\alpha 4$ expression. Importantly, Inhibition of PI3K/Akt inhibited Id 1 and integrin $\alpha 4$ expression, resulting in the decreasing biological function of EPCS.
\end{abstract}

Conclusions: Id 1 induced EPCs mobilization and recruitment is mediated chiefly by the PI3K/Akt signaling pathway and is associated with activation of integrin $\alpha 4$.

\section{Background}

Numerous studies have indicated that angiogenesis, a process mediated by endothelial progenitor cells (EPCs) derived from the bone marrow, is increased in many tumors due to elevated levels of angiogenic factors in the peripheral blood. An increase in EPCs supply and mobilization from the bone marrow can accelerate tumor angiogenesis [1-3]. A number of reports have described the incorporation of EPCs into tumor vessels in both tumor models and human patients. However the mechanisms that govern the behavior of EPCs, from their origin in the BM to their release into the circulation in response to pro-angiogenic stimuli, are still poorly understood $[4,5]$.

\footnotetext{
* Correspondence: nfyyzl@163.com; nflab@163.com

*Correspondence: nfyyzl@163.com; nflab@163.com
Department of Clinical Laboratory, Nanfang Hospital, Southern Medical University, Guangzhou, China
}

( 2010 Su et al; licensee BioMed Central Ltd. This is an Open Access article distributed under the terms of the Creative Commons Attribution License (http://creativecommons.org/licenses/by/2.0), which permits unrestricted use, distribution, and reproduction in any medium, provided the original work is properly cited. known to inhibit the activity of basic helix loop helix transcription factors by blocking their ability to bind DNA [6]. Loss of Id1 in the BM leads to a complete loss of EPCs in peripheral blood, which has been correlated with a block in tumor neovascularization and delayed tumor growth [7]. However, the actual role of Id1 in regulating EPCs mobilization or recruitment remains unknown. Given the key roles that EPCs migration and adhesion may play in tumor metastasis, we tried to investigate the effect of Id1 on circulating EPCs mobilization and recruitment and the possible signal transduction pathways involved in the process.

We knocked down the expression of Id1 by an siRNAmediated Id1 lentiviral construct to determine the functional importance of Id1 in EPCs of patients with ovarian cancer,. Our results indicate that Id1 contributes to the migration and adhesion of EPCs in ovarian cancer 
patients and that Id1 may be important in the pathogenesis of ovarian cancer. Next, we evaluated the effects of inhibiting the phosphatidylinositol 3-kinase (PI3K)/Akt signaling pathway on Id1 and integrin $\alpha 4$ in EPCs of patients with ovarian cancer.

The identification of Id1 as a common target gene in EPCs migration and adhesion suggested that Id1 might serve as a novel therapeutic target in ovarian cancer. Id1 is expressed in bone marrow-derived EPCs [8] and is highly expressed in ovarian cancer cells $[9,10]$. Inhibiting Id1 can therefore both disrupt ovarian cancer cells growth and prevent blood vessels from feeding the ovarian cancer cells.

\section{Methods}

\section{Patients}

This study was approved by the local ethics committee in China and informed consent was obtained from all study participants. Twenty-five patients (median age, 41 years old; age range, 21-59 years old) with histologically proven ovarian cancer, including serous cancer $(\mathrm{n}=14)$, mucinous cancer $(n=7)$, and endometrioid cancer $(\mathrm{n}=4)$, were studied along with a control group of healthy women $(n=20$, age range, $18-35$ years old). These diagnosed ovarian cancer patients had no additional malignant, inflammatory, or ischemic disease; wounds; or ulcers that could influence the number of EPCs.

\section{EPCs isolation and characterization}

Total MNCs were isolated from $20 \mathrm{ml}$ human peripheral blood samples from ovarian cancer patients and healthy women by density gradient centrifugation with Histopaque-1077 (density $1.077 \mathrm{~g} / \mathrm{ml}$; Sigma). MNCs were plated in $1 \mathrm{ml}$ endothelial growth medium (EGM-2; Lonza) on fibronectin-coated (Sigma) twenty-four-well plates. After $24 \mathrm{~h}$ of culturing, unattached cells were discarded and attached cells were cultured as before. Medium was replaced every 2 days thereafter, and each colony/cluster was followed up. After 7 days in culture, colony forming cells were recognized as attached spindle-shaped cells. The adherent cells were incubated with DiI-acLDL (Molecule Probes) and then fixed in 2\% paraformaldehyde and counterstained with fluorescein isothiocyanate (FITC)-labeled lectin from ulex europaeus agglutinin (UEA-1) (Sigma). The fluorescent images were recorded under a fluorescent microscope. Cells were also characterized by immunofluorescence staining for von Willebrand factor (vWF) and expression of CD31 and VEGFR2 (Becton Dickinson).

\section{Quantitative real-time RT-PCR}

Total RNA isolation and cDNA synthesis from cultured EPCs were performed using Trizol and the SuperScript
II Reverse Transcriptase kit (Invitrogen, USA) according to the manufacturer's instructions.

Real-time PCR was performed with the Mx3000p Real Time PCR System (Stratagene, USA) using the following thermal cycling conditions: $10 \mathrm{sec}$ at $95^{\circ} \mathrm{C}$ followed by 40 cycles of $15 \mathrm{sec}$ at $95^{\circ} \mathrm{C}, 20 \mathrm{sec}$ at $60^{\circ} \mathrm{C}$, and $7 \mathrm{sec}$ at $72^{\circ} \mathrm{C}$. SYBR ${ }^{\circ}$ GreenER qPCR SuperMix Universal $\mathrm{S}$ (Invitrogen, USA) $(25 \mu \mathrm{l})$ were performed in triplicate. A no-template control (replacing RNA with water) was used as a negative control. Id1 and integrin $\alpha 4$ mRNA in the EPCs was determined by relative quantitation, interpolating from a standard curve of template DNA of known concentration and then normalized using $\beta$-actin as an internal control. Data were analyzed by $2^{-\Delta \Delta \mathrm{Ct}}$.

The primer sequences used for real-time PCR were as follows: Id1, 5-GTAAACGTGCTGCTCTACGACATGA-3 and 5-AGCTCCAACTGAAGGTCCCTGA-3; integrin $\alpha 4,5$-TTGACAACAACGGTACTGCTAC-3 and 5-TGGTGAACACTGTGCTGATTAC-3; and $\beta$-actin, 5-TGGCACCCAGCACAATGAA-3 and 5-CTAAGTCATAGTCCGCCTAGAAGCA-3.

\section{Western blots}

The EPCs were collected with sample buffer. Cell lysates were centrifuged at $10000 \mathrm{~g}$ for $10 \mathrm{~min}$ at $4^{\circ} \mathrm{C}$ and the supernatant was stored at $-70^{\circ} \mathrm{C}$. Protein concentrations were determined with a Bio-Rad kit. 50- $\mu$ g aliquots of protein were subjected to $12 \%$ and 6\% SDS-PAGE gels. Then the protein was blotted onto a PVDF membrane. Primary antibodies against Id1(1:1000, Becton Dickinson), integrin $\alpha 4$ (1:1000, Becton Dickinson), PhosphoAkt (ser473) (1:1000, Cell Signaling), Total-Akt (1:2000, Cell Signaling), and $\beta$-actin (1:2000, Becton Dickinson) were used according to the manufacturer's recommendations. After washing the membrane, a second antibody (HRP-conjugated anti-mouse IgG) (1:2000, Becton Dickinson) was used to detect Id1, integrin $\alpha 4$, PhosphoAkt, Total-Akt, and $\beta$-actin. The bands were visualized using the ECL detection system (Pierce) with 5 to $30 \mathrm{~min}$ exposure after washing the membrane. $\beta$-actin were used as protein loading controls.

\section{Construction of lentiviral vector expressing Id1-specific ShRNA}

Three different Id1-specific target sequences were chosen according to online siRNA tools provided by Invitrogen (http://www.invitrogen.com/rnai) using the Id1 reference sequence (Gene Bank Accession No NM_002165). Double-stranded DNA containing the interference sequences were synthesized according to the structure of a pGCSIL-GFP viral vector (Gikai gene company, Shanghai, China) and then inserted into a linearized vector. All the constructs were cloned and 
sequenced to confirm their structure. The positive clones were identified as lentiviral vectors that expressed human Id1 short hairpin RNA (shRNA), hereafter designated pGCSIL/Id1-1, pGCSIL/Id1-2, and pGCSIL/Id1-3. The three lentiviral vectors were transfected into HEK 293 cells separately to evaluate their RNA interference effects and pGCSIL/Id1-3 (sequence: 5'-gaCATGAACGGCTGTTACTCA-3') induced the highest levels of downregulation. So pGCSIL/Id1-3 vector and viral packaging system (Gikai gene company, Shanghai, China, containing an optimized mixture of two packaging plasmids: pHelper 1.0 vector and pHelper $2.0 \mathrm{vec}-$ tor) were cotransfected into 293 cells to replicate competent lentivirus. Viral supernatant was harvested $48 \mathrm{~h}$ after transfection, filtered through a $0.45-\mathrm{mm}$ cellulose acetate filter and frozen at $-70^{\circ} \mathrm{C}$. The lentivirus (LV) containing the human Id1 shRNA-expressing cassette (pGCSIL/Id1-3) was used as a positive control for lentivirus production and denoted as Id1-RNAi-LV in the next experiments. The pGCSIL/U6 mock vector was also packaged and used as a negative control, denoted as NC-GFP-LV. Viral concentrations were determined by serial dilutions of the concentrated vector stocks in 293 cells in 96-well plates. The number of green fluorescent protein (GFP)-positive cells was measured $4 \mathrm{~d}$ post-transduction under microscopy. The titers averaged $2 \times 10^{9} \mathrm{TU} / \mathrm{mL}$.

\section{In vitro transduction of EPCs}

For lentiviral transduction, the primary EPCs were passaged into 6 -well plates at a density of $1 \times 10^{5}$ cells/ well. When cells reached $30 \%$ confluence (typically on the third day after subculturing) the medium was replaced with $1 \mathrm{~mL}$ of fresh medium containing lentivirus at an MOI of 150 and $6 \mu \mathrm{g} / \mathrm{mL}$ polybrene (Gikai gene company, Shanghai, China). The medium was replaced with fresh medium on the following day. Five days after transduction cells were analyzed by flow cytometry using a BD FACSCalibur cell analyzer (BD Biosciences). The percentage of GFP-positive cells and mean fluorescence intensity (MFI) of GFP-positive cells were determined with WinMDI 2.8 software (J. Trotter, Flow Cytometry Core Facility, Scripps Research Institute, La Jolla, CA). Means and standard deviations from experiments performed in triplicate are given.

\section{Proliferation assay}

The 3-(4,5-dimethylthiazol-2-yl)-2,5-diphenyltetrazolium bromide (MTT) assay was used to determine EPCs proliferation. EPCs were incubated with $50-400 \mu \mathrm{g} / \mathrm{ml}$ AGE-albumin or $400 \mu \mathrm{g} / \mathrm{ml}$ unmodified albumin for 24 $\mathrm{h}$, then supplemented with MTT $(0.5 \mathrm{mg} / \mathrm{ml}$, Sigma $)$ and incubated for a further $4 \mathrm{~h}$. The blue formazan thus produced was solubilized with dimethyl sulfoxide and absorbance was measured at 550-650 $\mathrm{nm}$.

\section{Transwell Migration Assay}

After 7 days of incubation, culture medium was removed and replaced with EBM-2 without any supplement 12 hours before the migration assay. EPCs migration was evaluated using a transwell migration assay. Briefly, $5 \times 10^{4}$ cells were suspended in $100 \mu \mathrm{L}$ of EBM-2 supplemented with $0.1 \%$ BSA and placed in the upper chamber of an $8.0-\mathrm{mm}$ pore size transwell (Costar, Cambridge, MA). $600 \mu \mathrm{L}$ of the final dilution was placed in the lower chamber. After incubation for 6 hours at $37^{\circ} \mathrm{C}$ in $5 \% \mathrm{CO}_{2}$, the cells that had not migrated were removed from the upper surface of the filters using cotton swabs and those that migrated to the lower surface of the filters were fixed in methanol and stained with Giemsa's Stain Solution. Migration was determined by counting the cell number with a microscope. Five visual fields were randomly chosen for each assay. The average number of the migrating cells in these 5 fields was taken as the cell migration number of the group.

\section{Adhesion assay}

EPCs were labeled with 4, 6-diamidino-2-phenylindole (Roche Applied Science, Indianapolis, IN). After detachment and centrifugation, EPCs were resuspended in adhesion buffer (0.5\% bovine serum albumin in EBM-2) and identical numbers of cells were replated in fibronectin-coated 24-well culture plates, incubated for $60 \mathrm{~min}$ at $37^{\circ} \mathrm{C}$, and then washed 3 times gently with adhesion buffer to remove the nonadherent cells. The adherent cells were counted by fluorescence microscopy at $\times 200$ magnification. Five independent fields were assessed for each well, and the average number of adherent cells per $\times 200$ field was determined.

To evaluate the ability of EPCs to adhere to confluent vascular endothelial cells, human vascular endothelial cells were cultured in 1640 medium containing $10 \%$ fetal bovine serum (Gibco) and served as a matrix for the adhesion assay. Briefly, a monolayer of vascular endothelial cells was prepared in 24-well culture plates $48 \mathrm{~h}$ before the assay. EPCs were labeled with 5,6-carboxyfluorescein diacetate, succinimidyl ester (CFSE). Finally, EPCs were added to each well and incubated for $3 \mathrm{~h}$ at $37^{\circ} \mathrm{C}$. Nonattached cells were gently removed with $\mathrm{PBS}$ and adherent cells were fixed with $4 \%$ paraformaldehyde and counted in five random fields under $200 \times$ magnification. The results obtained revealed essentially unchanged results during a 4-week observational period with a variation coefficient less than $6 \%$. 


\section{Statistical analysis}

Statistical analyses were performed with Statistical Package for Social Sciences 13.0 software program (SPSS, USA). The Mann-Whitney U test and Student's t-test were used to compare variables between the two groups. Multiple comparisons were analyzed by Anova followed by post-hoc analysis to adjust the significance level. Data are shown as means \pm S.E. Statistical significance was considered as $\mathrm{P}<0.05$.

\section{Results}

\section{Characterization of EPCs}

After 7 days of culture, ex vivo expanded EPCs derived from peripheral blood of healthy human volunteers and ovarian cancer patients exhibited spindle-shaped morphology. EPCs were characterized as adherent and double positive for Dil-Ac-LDL uptake and lectin binding based on their appearance in a fluorescent microscope. A total of $93.8 \pm 4.5 \%$ of adherent cells showed uptake of Dil-Ac-LDL and lectin binding after 7 days of culture in our study. The endothelial phenotype of these expanded EPCs was further characterized by the expression of endothelial markers such as von willebrand factor, CD31, and VEGFR2. Immunofluorescence showed that the cells were positive for vWF, CD31, and VEGFR2 (Figure. 1).

\section{Id1-RNAi-LV transfection inhibited the expression of Id1 mRNA and protein in EPCs}

We used real-time RT-PCR to examine mRNA expression of Id1 in EPCs of 25 patients with ovarian cancer, and Western blot analysis revealed a higher Id1 protein expression in human ovarian cancer EPCs than in 20 healthy controls. To confirm the role of Id1 in EPCs of patients with ovarian cancer we performed gene-silencing experiments. EPCs were transfected with lentiviralId1-siRNA vector. The negative control containing pGCSIL/U6 mock vector only was denoted NC-GFP-LV. After the Id1-RNAi-LV construct was transfected into EPCs of 6 patients with ovarian cancer, Id1 mRNA expression levels in transfected cells were compared to those in nontransfected and control-transfected (NCGFP-LV) EPCs of 6 patients with ovarian cancer by quantitative RT-PCR. Cells with Id1-RNAi-LV transfection showed a $72 \%$ reduction in the level of Id1mRNA expression (Figure 2A). To further confirm the specificity of Id1-RNAi-LV-mediated Id1 silencing, Id1 protein expression was determined by Western blot. As shown in Figure 2B-C, Id 1 protein expression in EPCs of 6 patients with ovarian cancer transfected with Id1-RNALV was significantly decreased compared to that in control EPCs. These results indicate that lentivirusmediated RNAi was an effective way of modulating Id1 expression in cultured EPCs.
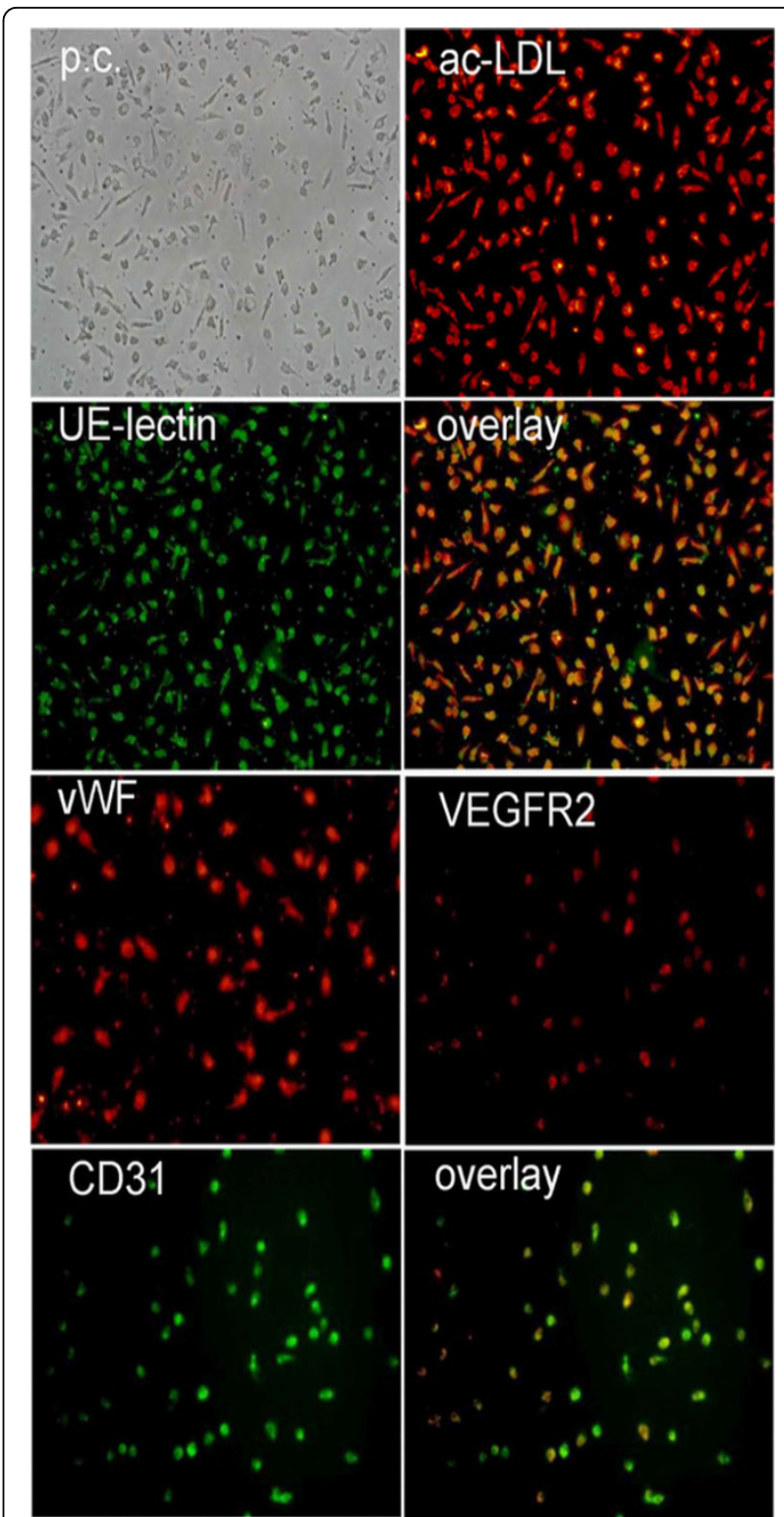

Figure 1 Phenotypic characterization of EPCs from human peripheral blood. After a week in culture, EPCs were stained with DIL-labeled ac-LDL, FITC-conjugated Ulex europaeus lectin and double stained with DIL-labeled ac-LDL and FITC-conjugated Ulex europaeus lectin (overlay). von Willebrand factor (VWF), VEGFR2 CD31 and double stained with VEGFR2 and CD31 (overlay) analysis were assessed by immunofluorescence $(\times 20)$.

\section{Effects of Id1-RNAi-LV on EPCs proliferation, migration} and adhesion

To examine EPCs functions in ovarian cancer we examined the proliferation, migration, and adhesion of EPCs. Proliferation, migration, and adhesion of EPCs are important for mobilization and recruitment. The EPCs of ovarian cancer patients showed increased migration and adhesion to fibronectin and endothelial cells. 


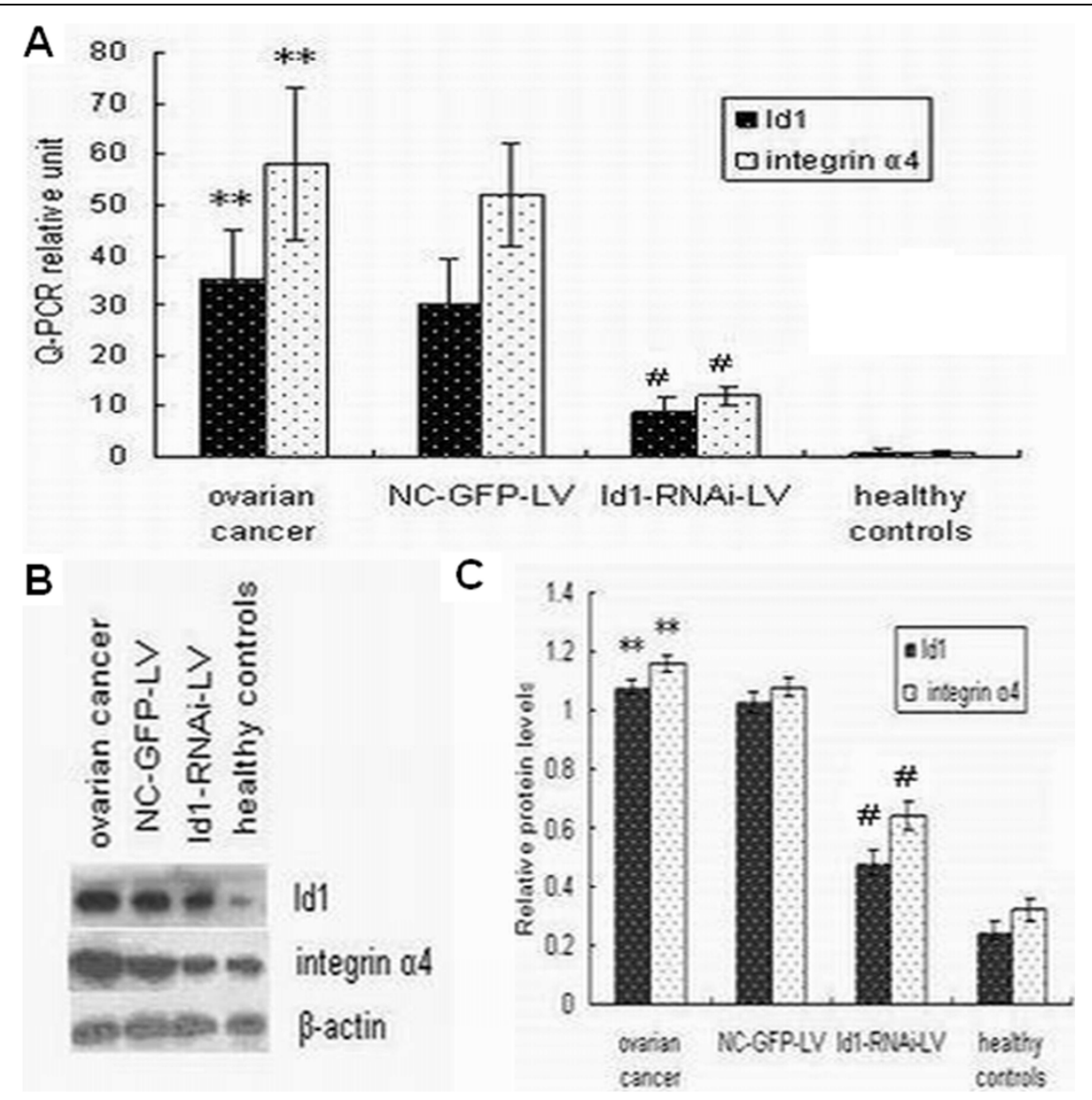

Figure 2 Id1-RNAi-LV transfection silenced the mRNA and protein expression of Id 1 and integrin $\boldsymbol{\alpha} \mathbf{4}$ in EPCs. (A) Id 1 and integrin $\alpha 4$ mRNA expression by real-time RT-PCR. Data are expressed as means \pm S.E. ${ }^{* *} p<0.01$ vs control, ${ }^{*} p<0.05$ vs ovarian cancer. (B) Typical Western blot images showing protein expression of $\mathrm{Id} 1$ and integrin $\alpha 4$ ( $\beta$-actin is shown as a housekeeping control). (C) The graph showing the relative Id1 and integrin $\alpha 4$ protein levels normalized to $\beta$-actin. The results were expressed as the mean \pm S.E. ${ }^{* *} p<0.01$ vs. control, ${ }^{\#} p<0.05$ vs. ovarian cancer.

Statistical analyses revealed that ovarian cancer enhanced EPCs proliferation, migration, and adhesion.

After the Id1-RNAi-LV construct was transfected into EPCs, the cells were cultured for 7 days and we then performed EPCs proliferation, migration, and adhesion analysis. Id1-RNAi-LV markedly reduced EPCs functions. Cells transfected with Id1-RNAi-LV displayed less proliferation, migration, and adhesion abilities compared to non-transfected control cells, as shown in Figure 3A-D. Cells transfected with NC-GFP-LV, on the other hand, exhibited no change in cell proliferation, migration, and adhesion abilities, compared to non-transfected control EPCs. These data indicate that Id1 is crucial for the mobilization and recruitment of EPCs in ovarian cancer.

\section{Id1-RNAi-LV transfection inhibited the expression of integrin $\alpha 4 \mathrm{mRNA}$ and protein in EPCs}

To explain the effect of Id1 on migration toward peripheral blood and recruitment to tumor tissues we explored the expression of integrin $\alpha 4$ on the EPCs surface of 25 patients with ovarian cancer. In keeping with the mRNA results, Western blots showed increased integrin $\alpha 4$ protein expression in EPCs.

After the Id1-RNAi-LV construct was transfected into EPCs of 6 patients with ovarian cancer, integrin $\alpha 4$ mRNA expression levels in transfected cells were compared to those in nontransfected and controltransfected (NC-GFP-LV) EPCs of 6 patients with ovarian cancer by quantitative RT-PCR. Cells with Id1RNAi-LV transfection showed a $65 \%$ reduction in integrin $\alpha 4$ mRNA expression (Figure 2A). Integrin $\alpha 4$ protein expression was then determined by Western blot. As shown in Figure 2B, integrin $\alpha 4$ protein expression in EPCs transfected with Id1-RNA-LV was significantly decreased compared to that in control EPCs. These results indicate that the effect of Id1 on adhesion and angiogenesis is associated with activation of integrin $\alpha 4$. 


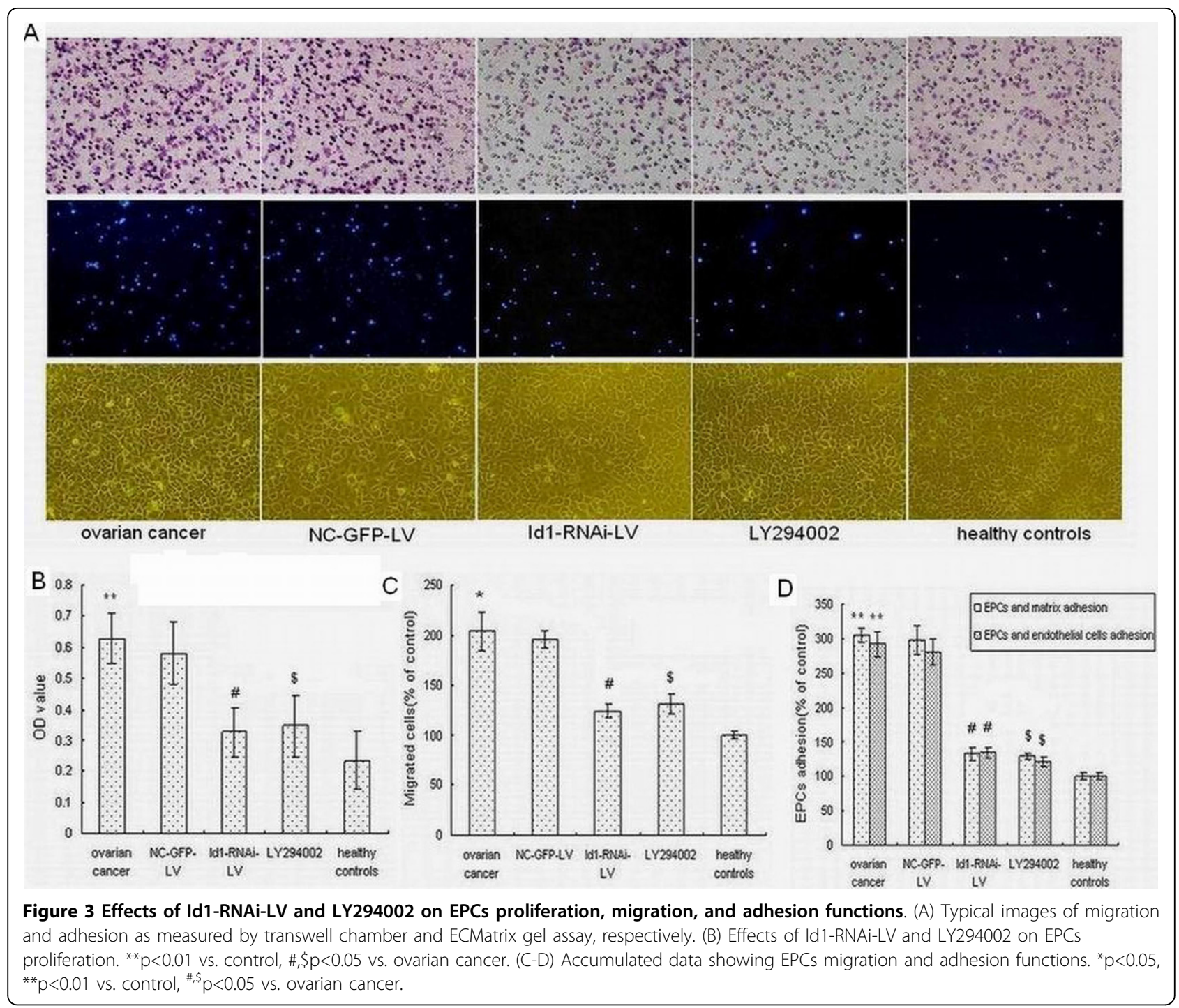

\section{Effects of PI3K/Akt on Id1, integrin $\alpha 4$, and EPCs functions}

EPCs use a broad spectrum of mobilization and recruitment mechanisms to achieve with enhanced tumor metastasis (Shaked et al. 2006). To begin to determine which signaling transduction pathways might participate in Id1-mediated cell mobilization and recruitment in EPCs, we investigated PI3K/AKT pathway using pharmacological inhibitors. Elevated AKT-Ser473 phosphorylation was observed in EPCs, and it was completely abolished by LY294002 ( $1 \mu \mathrm{mol} / \mathrm{L})$. As Figure 4A-B shows, Id 1 and integrin $\alpha 4$ expression were also strongly decreased by LY294002. Figure 3A-D show that EPCs of patients with ovarian cancer had increased levels of cell proliferation, migration and adhesion, which were strongly decreased by incubation with LY294002. These results indicate that Id1-induced EPCs mobilization and recruitment is mediated by the PI3K/AKT pathway. Thus Id1 induced migration and adhesion of EPCs is mediated by an increase in integrin $\alpha 4$ expression and is regulated by the PI3K/Akt pathway.

\section{Discussion}

Ovarian cancer is one of the most aggressive gynecological malignancies and its high mortality is most often a direct result of delays in diagnosis. Only $25 \%$ of ovarian cancers are diagnosed while the malignancy is still confined to the ovary, and the cure rate in these patients can reach $90 \%$. The remaining $75 \%$ of ovarian tumors have spread beyond the ovary by the time of diagnosis and the cure rate for these patients is less than $20 \%$ [11]. With the advent of molecular-targeted therapies, treatment for ovarian cancer is now moving beyond conventional chemotherapy. Inhibition of the specific 


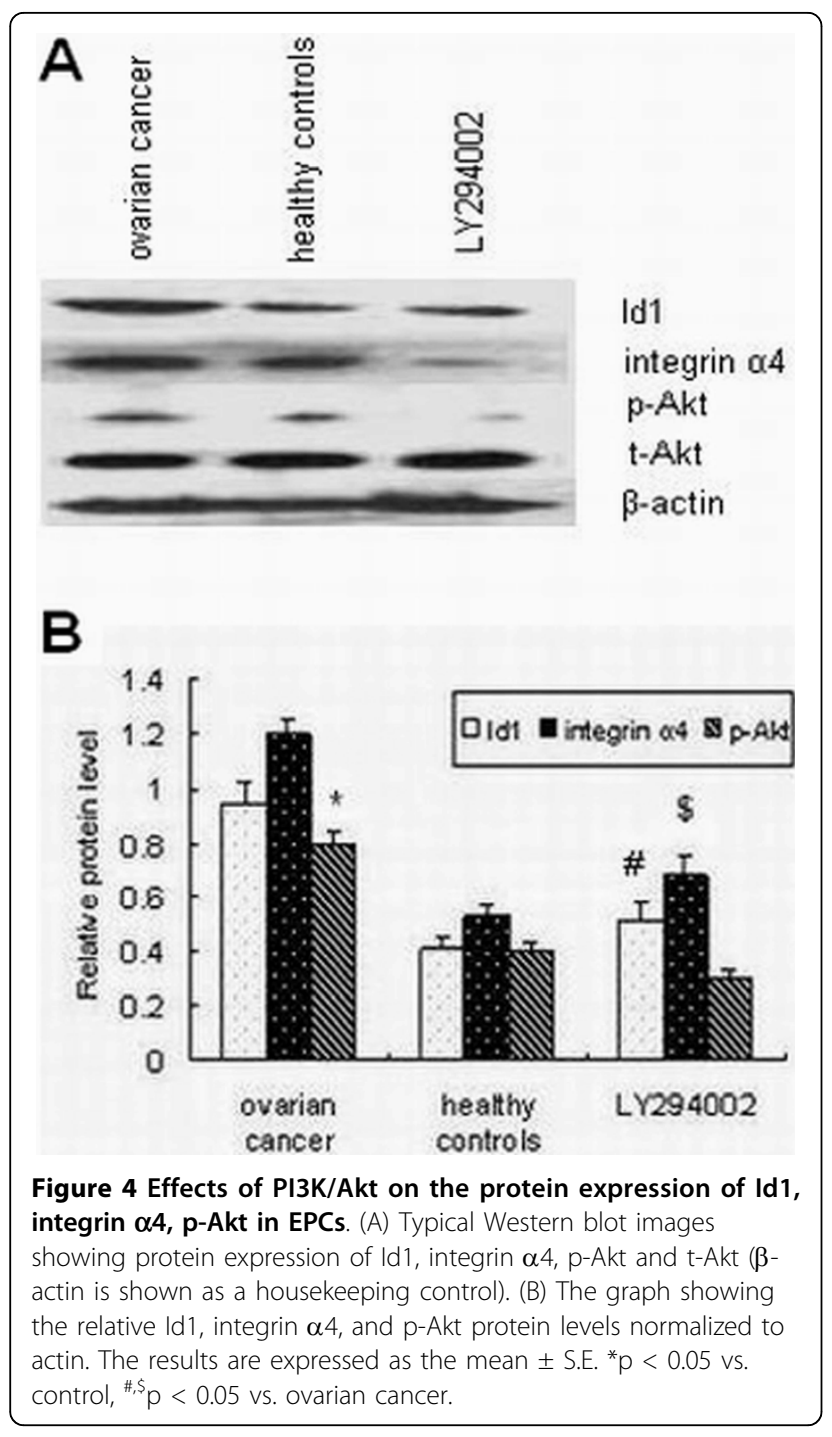

cytokines essential for tumor vascularization is such a therapy [12]. Thus anti-angiogenesis therapy has become a new strategy for ovarian cancer treatment [13].

Evidence continues to accumulate confirming the importance of EPCs in the neovascularization of tumor tissues. Many researchers have focused on EPCs biology and potential clinical applications [14-16]. Previous studies have suggested that bone marrow-derived EPCs can migrate to tumor foci and promote tumor growth and metastasis. However, the signals that mediate mobilization and recruitment of these cells to tumors are not well understood. We showed previously that EPCs numbers are increased in ovarian cancer patients and EPCs numbers were related to tumor progression and angiogenesis. Here, using blood samples from 25 ovarian cancer patients, we demonstrated that Id1 is involved in enhancing EPCs migration and adhesion. Id1 may mediate EPCs mobilization and recruitment to ovarian cancer tissues.
We further explored the effect of Id1 and related signaling pathways on EPCs of patients with ovarian cancer.

Id1 has been implicated in a variety of cellular processes including cell growth, differentiation, angiogenesis, and neoplastic transformation. Id1 is expressed in various tumor tissues and cells [17]. Id1 knockout mice were critical in demonstrating that BM-derived progenitors are the source of tumor endothelium in some tumor types and grades, as Id1 knockout mice failed to mobilize these progenitors and transplantation of Id1 knockout mice with wild type BM was shown to rescue the observed vascular defects $[8,18]$. The importance of Id1+ progenitor cells in vascular rebound was confirmed recently by results from vascular disrupting therapies [19]. The mechanism by which Id1 controls the generation of EPCs is also beginning to be explored. In recent studies, Id1 was shown to be expressed in long term repopulating hematopoietic stem cells (lin- Sca+ kit+ CD34-) in the BM and Id1 loss was shown to lead to an upregulation of the expression of the cyclin-dependent kinase inhibitor p21. The expression of p21 in turn drives the stem cells towards a more committed myeloid state, as assessed by gene expression profiling; this myeloid differentiation is associated with the depletion of cells capable of endothelial cell fate commitment $[20,21]$. These results suggest that Id 1 is required in early hematopoietic stem cells to restrain the commitment to the myeloid lineage and preserve a pool of cells that give rise to endothelial progenitors in response to vasculogenic growth signals. Although Id1 and Id3 are thought to be functionally redundant in many cell types $[1,22]$. It is not yet known if this is the case in EPCs.

In this study we show an essential role for Id 1 in EPCs mobilization and recruitment to the tumor. Our real-time RT-PCR analysis indicates that Id1 expression in ovarian cancer is significantly increased compared to that in healthy subjects. Importantly, EPCs isolated from ovarian cancer patients display increased integrin $\alpha 4$ expression and baseline migration and adhesion. This is interesting in light of a recent report showing that integrin $\alpha 4$ promotes the homing of circulating progenitor cells and other bone marrow-derived mononuclear circulating cells not only to tumor tissues but also to inflamed and ischemic tissues [23]. To determine the role of Id1 in EPCs, we repressed its expression. As expected, transfection of EPCs with Id1-special siRNA silenced Id1 expression and abolished upregulation of integrin $\alpha 4$. Furthermore, migration and adhesion were both inhibited in EPCs when they were transduced with Id1-RNAi-LV. This indicates that Id1 is important for EPCs migration and adhesion. Our data demonstrate that down-regulation of Id 1 may reduce the expression of integrin $\alpha 4$, thereby contributing to the functional inhibition we observed in our study. 
Little is known about the molecular signaling pathways underlying EPCs mobilization and recruitment, particularly in ovarian cancer patients. It has been shown that Id1 is an important regulator for the fate of hematopoietic stem cells. In this study, we showed that high Id1 in EPCs is mediated by the PI3K/Akt pathway, a key pathway in mediating vasculogenesis. We also demonstrated that ovarian cancer activated the PI3K/ Akt signaling pathway in EPCs. This is a novel finding. Therefore, we concluded that signaling through the P13K/Akt signaling pathway upregulates Id1, which enhances mobilization and recruitment via integrin $\alpha 4$. We showed that Akt is phosphorylated in EPCs of ovarian cancer patients, and inhibition of PI3K/Akt downregulated the expression level of Id 1 and integrin $\alpha 4$ and reduced EPCs functions. Taken together, our data support the notion that ovarian cancer EPCs migration and recruitment via the PI3K/Akt-Id1 - integrin $\alpha 4$ signaling pathway may be responsible for increased EPCs levels in ovarian cancer.

\section{Conclusions}

We showed that Id1 induced proliferation, migration and adhesion of human EPCs via the PI3K and Akt signaling pathway. Our data also provide further insights into the understanding of neovascularization. These findings raise the possibility that therapeutic strategies aiming to reduce EPCs angiogenesis have a two pronged effect: they might enhance the efficacy of certain cytotoxic anti-angiogenesis ovarian cancer therapies while at the same time reducing the risk of ovarian cancer metastases.

\section{Acknowledgements \\ The study was supported in part by the Ministry of Health research funds of China (No. WKJ2007-3-001) and the Provincial Natural Science Foundation (No. 07300312). \\ Authors' contributions \\ YS participated in study design, carried out most of the experiments, and drafted the manuscript. LZ participated in collecting samples and manuscript preparation. QW conceived of the study, and participated in its design and coordination. JB assisted with cell culture. ZC participated in study design and statistical analysis. AL assisted with the critical revision of the manuscript. All authors read and approved the final manuscript.}

\section{Competing interests}

The authors declare that they have no competing interests.

Received: 31 March 2010 Accepted: 26 August 2010

Published: 26 August 2010

\section{References}

1. Lyden D, Young AZ, Zagzag D, Yan W, Gerald W, O'Reilly R, Bader BL, Hynes RO, Zhuang Y, Manova K, Benezra R: Id1 and Id3 are required for neurogenesis, angiogenesis and vascularization of tumour xenografts. Nature 1999, 401(6754):670-677.
2. Bertolini F, Shaked Y, Mancuso P, Kerbel RS: The multifaceted circulating endothelial cell in cancer: towards marker and target identification. Nature Reviews Cancer 2006, 6(11):835-845.

3. Young PP, Vaughan DE, Hatzopoulos AK: Biologic properties of endothelial progenitor cells and their potential for cell therapy. Prog Cardiovasc Dis 2007, 49(6):421-429.

4. Li B, Sharpe EE, Maupin AB, Teleron AA, Pyle AL, Carmeliet P, Young PP: VEGF and PIGF promote adult vasculogenesis by enhancing EPC recruitment and vessel formation at the site of tumor neovascularization. FASEB J 2006, 20(9):1495-1497.

5. Stoelting S, Trefzer T, Kisro J, Steinke A, Wagner T, Peters SO: Low-dose oral metronomic chemotherapy prevents mobilization of endothelial progenitor cells into the blood of cancer patients. In Vivo 2000, 822(6):831-836.

6. Perk Jonathan, Gil-Bazo Ignacio, Chin Yvette, de Candia Paola, Chen John JS, Zhao Yuntao, Chao Shirley, Cheong Wai, Ke Yaohuang, AlAhmadie Hikmat, Gerald William L, Brogi Edi, Benezra Robert: Reassessment of Id1 protein expression in human mammary, prostate, and bladder cancers using a monospecific rabbit monoclonal anti-ld1 antibody. Cancer Res 2006, 66(22):10870-10877.

7. Shaked Y, Ciarrocchi A, Franco M, Lee CR, Man S, Cheung AM, Hicklin DJ, Chaplin D, Foster FS, Benezra R, Kerbel RS: Therapy-induced acute recruitment of circulating endothelial progenitor cells to tumors. Science 2006, 313(5794):1785-1787.

8. Gao D, Nolan DJ, Mellick AS, Bambino K, McDonnell K, Mittal V: Endothelial progenitor cells control the angiogenic switch in mouse lung metastasis. Science 2008, 319(5860):195-198.

9. Maw MK, Fujimoto J, Tamaya T: Overexpression of inhibitor of DNAbinding (ID)-1 protein related to angiogenesis in tumor advancement of ovarian cancers. BMC Cancer 2009, 10(9):430.

10. Zhang $X$, Ling MT, Feng H, Wong YC, Tsao SW, Wang X: Id-I stimulates cell proliferation through activation of EGFR in ovarian cancer cells. $\mathrm{Br} J$ Cancer Dec 2004, 91(12):2042-2047.

11. Lorusso D, Ferrandina G, Graggi S, Gadduci A, Pignata S, Tateo S, Biamonte R, Manzione L, Di Vagno G, Ferrau F, Scambia G: Phase III multicenter randomized trial of amifostine as cytoprotect-ant in first-line chemotherapy in ovarian cancer patients. Ann Oncol 2003, 14(7):1086-1093

12. Melichar B, Urbanek L, Krcmova L, Kalabova H, Svobodova I, Drag-ounova E, Vesely P, Hyspler R, Solichova D: Urinary neopterin in patients with ovarian cancer. Pteridines 2006, 17(4):145-153.

13. Spannuth WA, Sood AK, Coleman RL: Angiogenesis as a strategic target for ovarian cancer therapy. Nat Clin Pract Oncol 2008, 5(4):194-204.

14. Khan ZA, Melero-Martin JM, Wu X, Paruchuri S, Boscolo E, Mulliken JB, Bischoff J: Endothelial progenitor cells from infantile hemangioma and umbilical cord blood display unique cellular responses to endostatin. Blood 2006, 108(3):915-921.

15. Dome B, Timar J, Dobos J, Meszaros L, Raso E, Paku S, Kenessey I, Ostoros G, Magyar M, Ladanyi A, Bogos K, Tovari J: Identification and clinical significance of circulating endothelial progenitor cells in human non-small cell lung cancer. Cancer Res 2006, 66(14):7341-7347.

16. Khoo CP, Pozzilli P, Alison MR: Endothelial progenitor cells and their potential therapeutic applications. Regen Med 2008, 3(6):863-876.

17. de Candia P, Benera R, Solit DB: A role for Id proteins in mammary gland physiology and tumorigenesis. Adv Cancer Res 2004, 92:81-94.

18. Shaked Yuval, Ciarrocchi Alessia, Franco Marcela, Lee Christina R, Man Shan, Cheung Alison M, Hicklin Daniel J, Chaplin David, Stuart Foster F, Benezra Robert, Kerbel Robert S: Therapy-induced acute recruitment of circulating endothelial progenitor cells to tumors. Science 2006, 313(5794):1785-1787.

19. Lyden D, Hattori K, Dias S, Costa C, Blaikie P, Butros L, Chadburn A, Heissig B, Marks W, Witte L, Wu Y, Hicklin D, Zhu Z, Hackett NR, Crystal RG, Moore MA, Hajjar KA, Manova K, Benezra R, Rafii S: Impaired recruitment of bone-marrow-derived endothelial and hematopoietic precursor cells blocks tumor angiogenesis and growth. Nat Med 2001, 7(11):1194-1201.

20. Ciarrocchi A, Jankovic V, Shaked Y, Nolan DJ, Mittal V, Kerbel RS, Nimer SD, Benezra R: Id1 restrains p21 expression to control endothelial progenitor cell formation. PLOS One 2007, 2(12):e1338.

21. Qian $Y$, Chen X: ID1, inhibitor of differentiation/DNA binding, is an effector of the p53-dependent DNA damage response pathway. J Biol Chem 2008, 283(33):22410-22416. 
22. Benezra R, Rafii S, Lyden D: The Id proteins and angiogenesis. Oncogene 2001, 20(58):8334-8341.

23. Jin Hui, Aparna Aiyer, Su Jingmei, Per Borgstrom, Dwayne Stupack, Martin Friedlander, Varner Judy: A homing mechanism for bone marrowderived progenitor cell recruitment to the neovasculature. The Journal of Clinical Investigation 2006, 116(3):652-662.

\section{Pre-publication history}

The pre-publication history for this paper can be accessed here: http://www.biomedcentral.com/1471-2407/10/459/prepub

doi:10.1186/1471-2407-10-459

Cite this article as: Su et al:: The PI3K/Akt pathway upregulates Id 1 and integrin $\alpha 4$ to enhance recruitment of human ovarian cancer endothelial progenitor cells. BMC Cancer 2010 10:459.

Submit your next manuscript to BioMed Central and take full advantage of:

- Convenient online submission

- Thorough peer review

- No space constraints or color figure charges

- Immediate publication on acceptance

- Inclusion in PubMed, CAS, Scopus and Google Scholar

- Research which is freely available for redistribution

Submit your manuscript at www.biomedcentral.com/submit
C Biomed Central 